\title{
Устойчивое развитие в повестке архитектурного образования
}

\author{
Г.В.Есаулов, МАРХИ, Москва \\ Н.Г.Благовидова, МАРХИ, Москва \\ Ю.А.Табунщиков, МАРХИ, Москва
}

Область архитектуры и строительства ввиду большого влияния на окружающую среду является объектом регулирования посредством экологических доктрин. Однако в области профессионального и высшего архитектурного и строительного образования до настоящего времени не внедрена комплексная программа экологического образования. Ещё больше вопросов вызывает область градостроительного образования.

Ориентация деятельности на стратегию устойчивого развития заставляет архитектора и градостроителя искать адекватные и эффективные ответы на вызовы современности, опираясь на принципы этой стратегии.

В 2013 году в МАРХИ была разработана и в 2014-ом утверждена Концепция экологического образования. Предпосылки к её внедрению заложены в самой профессии архитектора и градостроителя, осуществляющих преобразование природного ландшафта в антропогенный. Цель Концепции, с одной стороны, обеспечить непрерывность процесса формирования экологического мышления на всех этапах учебного процесса, с другой стороны, она позволяет задействовать в архитектурном проектировании инновационные технологии в области экологического строительства, разработанные специалистами инженерных кафедр.

Сущность интегрированного архитектурного образования в овладении способностью разрабатывать и реализовывать социально-философскую идею устойчивой среды обитания для конкретных условий региона, города на основе современных научных и технических достижений в области градостроительства, архитектуры, экологической безопасности, конструкций, строительной физики и строительных материалов.

В основе этого подхода, названного «Интегрированное архитектурное образование», ориентированные на Стратегию устойчивого развития:

- разработанная многоуровневая система интегрированного устойчивого образования;

- проектирование объектов как устойчивых архитектурноинженерных умных систем;

- рейтинговая система оценки здания на протяжении всего жизненного цикла - от проектирования до различных стадий эксплуатации.

Ключевые слова: устойчивое развитие, архитектурное образование, методология, концепция экологического образования, интегрированные архитектурно-инженерные энергоэффективные системы, клаузура как инновационный инструмент.
Sustainability on the Agenda of Architectural Education

G.V. Yesaulov, MARCHI, Moscow

N.G. Blagovidova, MARCHI, Moscow

Yu.A. Tabunshchikov, MARCHI, Moscow

The field of architecture and construction, due to its great environmental impact, is subject to regulation through environmental doctrines. However, in the field of professional and higher architectural and construction education, a comprehensive environmental education program has not yet been implemented. The area of urban education raises even more questions.

The orientation of activities to the strategy of sustainable development forces the architect and urban planner to look for adequate and effective answers to the challenges of our time, based on the principles of the strategy.

In 2013, the Moscow Institute of Architecture developed the Concept of Environmental Education that was approved in 2014. The prerequisites for its implementation are laid down in the profession of an architect and urban planner, transforming the natural landscape into anthropogenic. The purpose of the Concept, on the one hand, is to ensure the continuity of the formation of environmental thinking at all stages of the educational process, on the other hand, it allows using innovative technologies in the field of environmental construction in architectural design developed by specialists from engineering departments.

The essence of integrated architectural education is the mastery of the ability to develop and implement the sociophilosophical idea of a sustainable environment for the specific conditions of the region, the city on the basis of modern scientific and technical achievements in the field of urban planning, architecture, environmental safety, structures, building physics, and building materials.

The basis of this approach, called Integrated Architectural Education, is focused on the Sustainable Development Strategy, which includes:

- multi-level system of environmental education;

- design of architectural and engineering energy-efficient systems;

- the assessment system of a building for its entire life cycle.

Keywords: sustainable development, architectural education, methodology, the concept of environmental education, integrated architectural and engineering energy-efficient systems, sketch as an innovative tool. 


\section{Введение}

Цель 11 доклада «0 целях в области устойчивого развития» $00 \mathrm{H}$ - «Обеспечение открытости, безопасности, жизнестойкости и экологической устойчивости городов и населённых пунктов» ${ }^{1}$ непосредственно относится к области профессионального интереса архитекторов и градостроителей, представителей архитектурной науки и образования.

Истоки этих подходов заложены в процессе сотрудничества Организации по образованию, науке и культуре при ООН (ЮНЕСКО) и ЮНЕП. Это привело в 1975 году к утверждению Международной программы экологического образования (МПЭП), целью которой было заявлено утверждение принципов экологического просвещения (ЭП). Основанием для формирования принципов стал ряд научных исследований, проводившихся под эгидой $00 \mathrm{H}$. Они охватили вопросы как образования, так и формирования общего, экологического просвещения, а именно:

1) вовлечение жителей - представителей различных социальных классов;

2) воспитание критического, этического и творческого мышления в оценке вопросов окружающей среды;

3) умение проводить обоснованные суждения по этим вопросам;

4) развитие навыков и привычки к самостоятельным и коллективным действиям по стабилизации и улучшению состояния окружающей среды;

5) повышение уважения к окружающей среде с целью последующего позитивного изменения поведения в сторону экологически осознанного [1].

Область архитектуры и строительства ввиду большого влияния на окружающую среду является объектом регулирования посредством экологических доктрин. Однако в области профессионального и высшего архитектурного и строительного образования до настоящего времени не внедрена комплексная программа экологического образования. Ещё больше вопросов вызывает область градостроительного образования ввиду междисциплинарности градостроительства как научной области и крайне сложного, политически ориентированного процесса регулирования вопросов устойчивого развития и его оценки. Существует и используется применительно к архитектурным объектам ряд рейтинговых систем оценки. Среди них международные и национальные рейтинговые системы устойчивости среды обитания: «Метод экологической оценки эффективности зданий» (BREEM, Великобритания), «Руководство по энергоэффективному и экологическому проектированию» (LEED, США), «Система комплексной оценки экологической эффективности зданий» (CASBEE, Япония) «Зелёная звезда» (GREEN STAR, Австралия), «Гонконгский Метод оценки экологичности строительства» (HК-BEAM) [2].

Следует отметить, что их использование носит добровольный характер и применяется зачастую для коммерческих

${ }^{1}$ Антониу Гутерреш, генеральный секретарь Организации Объединённых наций. Доклад «0 целях в области устойчивого развития». 2014 год зданий и сооружений, повышая их привлекательность и обеспечивая субсидии застройщикам.

Сегодня на мировом уровне разработаны индикаторы оценки экологического влияния архитектурной и градостроительной деятельности. Научное сообщество продолжает исследования и предлагает варианты комплексных индексов оценки. В их числе можно упомянуть созданные под эгидой Европейского союза и $00 \mathrm{H}$ «Барометр устойчивости», Индекс экологической эффективности (ЭПИ), Индекс развития человеческого потенциала (ИРЧП), показатели экоэффективности (ЮНКТАД) [3]. Индексы основаны на различных методиках расчёта и учёта факторов. В зарубежных программах высшего профессионального образования они присутствуют как составляющие в дополнительных дисциплинах.

Проблемы устойчивого развития в разных аспектах и разной степени затрагиваются практически в каждой дисциплине, изучаемой в современном вузе. При этом последующее использование индексов и рейтингов в архитектурном проектировании и городском планировании остаётся на усмотрение студента. Для европейской практики вопрос полноты комплексного внедрения принципов устойчивости в профессиональные программы обучения остаётся открытым. В настоящее время это осуществляется на уровне профессиональных объединений. В 2011 году принята Хартия об архитектурном образовании, подготовленная Международным союзом архитекторов (UIA - МСА) совместно с ЮНЕСКО [4]. В 2017 году на съезде МСА обсуждены вопросы повышения устойчивости архитектурностроительной отрасли в целом. В многочисленных статьях по вопросам экологического образования в архитектуре предложены разнообразные подходы к структуризации образования и методы оперирования принципами экологической стабильности на разных этапах образовательного процесса.

Согласно Хартии об архитектурном образовании «архитектура включает всё, что оказывает влияние на способы формирования антропогенной среды: её планирования, проектирования, воплощения, использования, оснащения, внешнего оформления и содержания», и поэтому «архитектурное образование утверждает один из важнейших экологических и профессиональных вызовов современного мира» [5]. Архитектурное образование должно вдохновлять на творчество и изобретения так же, как и на диалог, включённость и критическое мышление, для того чтобы усилить стремление к оперативному взаимодействию и групповому содружеству [6].

Ориентация деятельности на стратегию устойчивого развития заставляет архитектора и градостроителя искать адекватные и эффективные ответы на вызовы современности, опираясь на принципы этой стратегии.

В такой ситуации система образования должна, с одной стороны, обеспечить то, что сегодня заботит человечество. Потребности в проектной деятельности, в её осуществлении в стране, в разных регионах в различной степени ориентированы на урбанизацию с учётом потребностей населения, 
с другой стороны, образование должно дать возможность работать в будущем.

\section{Научно-педагогический подход. От методологии к методике}

Исходя из изложенного можно наметить некоторые векторы развития профессионального образования в области архитектуры и градостроительства как ответы на вызовы современного мира посредством реализации стратегии устойчивого развития.

Будущее профессионального образования многократно заявлено в его непрерывности: от школьной скамьи до завершающих этапов профессиональной карьеры. В этом определённая гарантия качества среды жизнедеятельности - его сохранения, поддержания и улучшения экологической устойчивости.

Многоступенчатость профессионального архитектурного, градостроительного и дизайнерского (дизайна архитектурной среды) образования сегодня закладывает фундаментальную базу такой непрерывности: бакалавриат, магистратура, повышение квалификации. Непрерывность обеспечивается синтезом векторов развития практики и науки.

В Московском архитектурном институте (государственной академии) в течение 2010-х годов укореняются принципы, обеспечивающие подготовку профессионалов, способных на основе стратегии устойчивого развития решать задачи, стоящие не только сегодня, но и те, которые будут поставлены завтра [7]. В основе этого подхода, названного «Интегрированное архитектурное образование», ориентированное на Стратегию устойчивого развития следующие составляющие.

- Разработанная многоуровневая система интегрированного устойчивого образования;

- Проектирование объектов как устойчивых архитектурно-инженерных умных систем;

- Рейтинговая система оценки здания на протяжении всего жизненного цикла - от проектирования до различных стадий эксплуатации.

В 2013 году в МАРХИ была разработана и в 2014-ом утверждена Концепция экологического образования. Предпосылки к её внедрению заложены в самой профессии архитектора и градостроителя, осуществляющих преобразование природного ландшафта в антропогенный. Цель Концепции, с одной стороны, обеспечить непрерывность процесса формирования экологического мышления на всех этапах учебного процесса, с другой стороны, она позволяет задействовать в архитектурном проектировании инновационные технологии в области экологического строительства, разработанные специалистами инженерных кафедр. Отличие предложенной Концепции от прежних в том, что они базировались на идее охранения природной среды и строились как системы правил и ограничений.

В основу Концепции, разработанной в МАРХИ, положен курс «Архитектурная экология», в котором важная роль отводится всестороннему анализу непрерывности процессов как в природной, так и в антропогенной среде. Сопровождает курс учебник «Архитектурная экология»², главная цель которого подготовить студентов к проектированию на основе концепции экологической безопасности и подвести к экспериментальному учебному проектированию в направлении комплексной экологизации.

Сущность интегрированного архитектурного образования в овладении способностью разрабатывать и реализовывать социально-философскую идею устойчивой среды обитания для конкретных условий региона, города на основе современных научных и технических достижений в области градостроительства, архитектуры, экологической безопасности, конструкций, строительной физики и строительных материалов. Оценка качества реализации социально-философской идеи осуществляется на основе специально разработанной рейтинговой системы, содержащей разнообразные показатели, что обеспечит:

- в социальной сфере - содействие социальному развитию и росту человеческого потенциала: обеспечение охраны здоровья и безопасности, обеспечение достойных условий труда и здорового образа жизни; обеспечение универсальной доступности для маломобильных групп населения, создание возможностей для малообеспеченных групп населения в формировании архитектурно-привлекательной среды, свободной от дискриминации;

- в экологической сфере - защита окружающей среды: строительство и проектирование зданий на основе «зелёных» стандартов, развитие практики управления зданиями с учётом принципов устойчивого развития, обеспечение эффективного энергопотребления и управления выбросами парниковых газов, обеспечение эффективного управления отходами, сведение к минимуму воздействия транспорта на окружающую среду, минимизация экологических рисков и сохранение биоразнообразия;

- в экономической сфере - содействие региональному экономическому развитию: экономическое развитие на региональном уровне, развитие инфраструктуры в целях стимулирования экономического развития на региональном уровне, содействие созданию рабочих мест, продвижение городов как центров туризма, содействие их благоустройству и росту привлекательности.

Проектирование объектов как интегрированных энергоэффективных систем. Интегрированное архитектурное образование, ориентированное на Стратегию устойчивого развития

Названный инновационный подход опирается на три принципа.

- Первый принцип - системное развитие профессиональных компетенций на взаимосвязи дисциплин, отражающих все сферы устойчивого развития.

${ }^{2}$ Е.М. Микулина. Архитектурная экология : учебник для студ. учреждений высш. проф. образования / Е. М. Микулина, Н. Г. Благовидова. - М. : Издательский центр «Академия», 2013. - 256 с. 

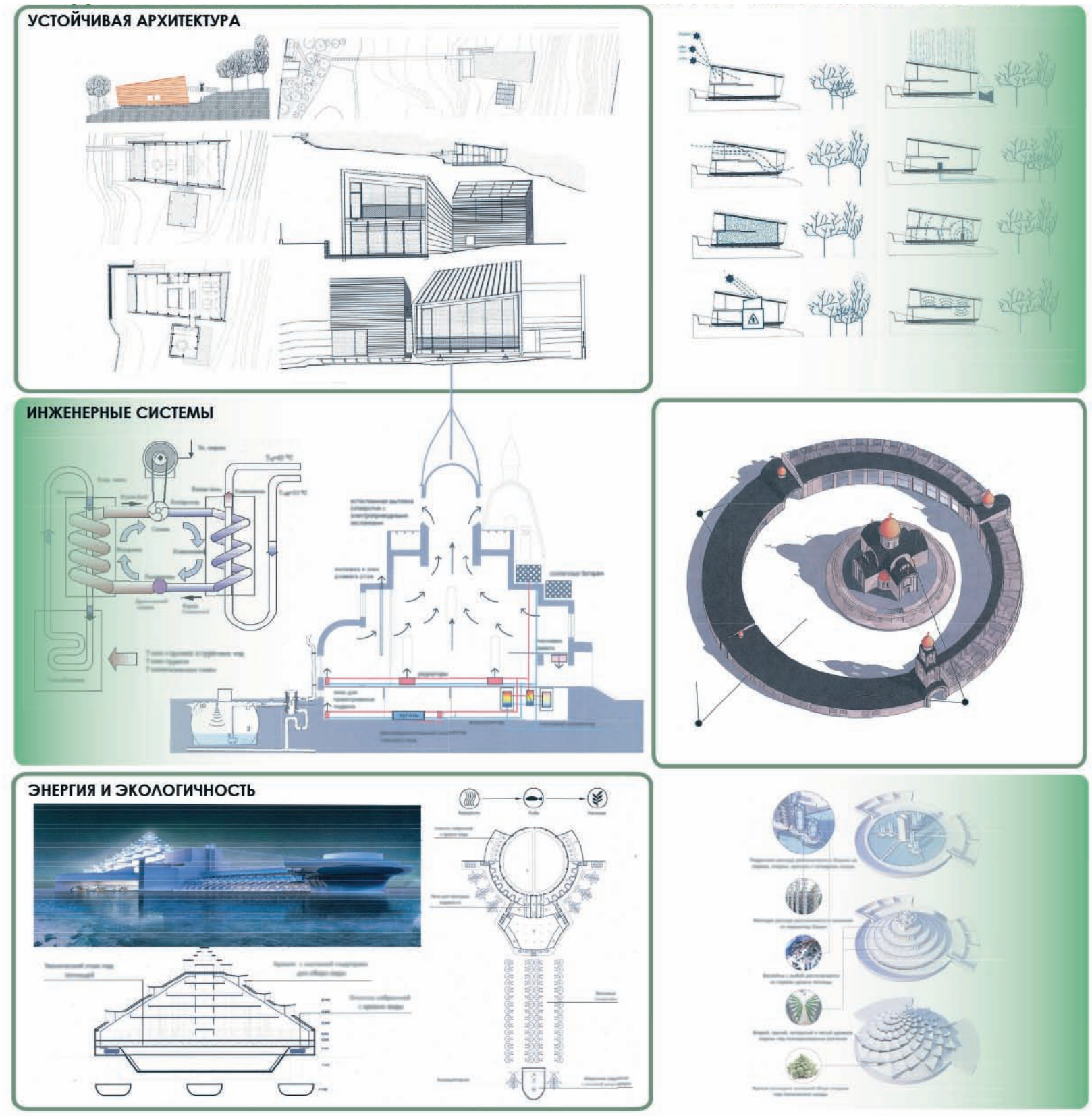

\begin{tabular}{|c|c|}
\hline 1 & $\begin{array}{l}\text { КОМФОРТ И КАЧЕСТВО } \\
\text { АРХИТЕКТУРНО-ПРОСТРАНСТВЕННОЙ СРЕ }\end{array}$ \\
\hline 2 & $\begin{array}{l}\text { АРХИТЕКТУРНО-ПААНИРОВОЧНАЯ КОНЦЕЕ } \\
\text { ЗААНИЯ }\end{array}$ \\
\hline 3 & $\begin{array}{l}\text { ЭНЕРГОЭФФЕКТИВНОСТЬ ОГРАЖААЮШИ } \\
\text { КОНСТРУКЦИЙ }\end{array}$ \\
\hline 4 & ИСТОЧНИКИ ТЕПАОЭНЕРГОСНАБЖЕНИЯ \\
\hline 5 & ИНТЕААЕКТУААИЗАЦИЯ ЗААНИЯ \\
\hline 6 & МИКРОКАИМАТ И ЭНЕРГОСБЕРЕЖЕНИЕ \\
\hline 7 & РАЦИОНААЬНОЕ ВОАОПОАЬЗОВАНИЕ \\
\hline 8 & ЭКОАОГИЧЕСКАЯ БЕЗОПАСНОСТЬ \\
\hline 9 & ИННОВАЦИОННЫЕ ПРЕМАОЖЕНИЯ \\
\hline
\end{tabular}

Оценки
max. 68
max. 63
max. 20
max. 60
max. 35
max. 33
max. 28
max. 26
max. 20
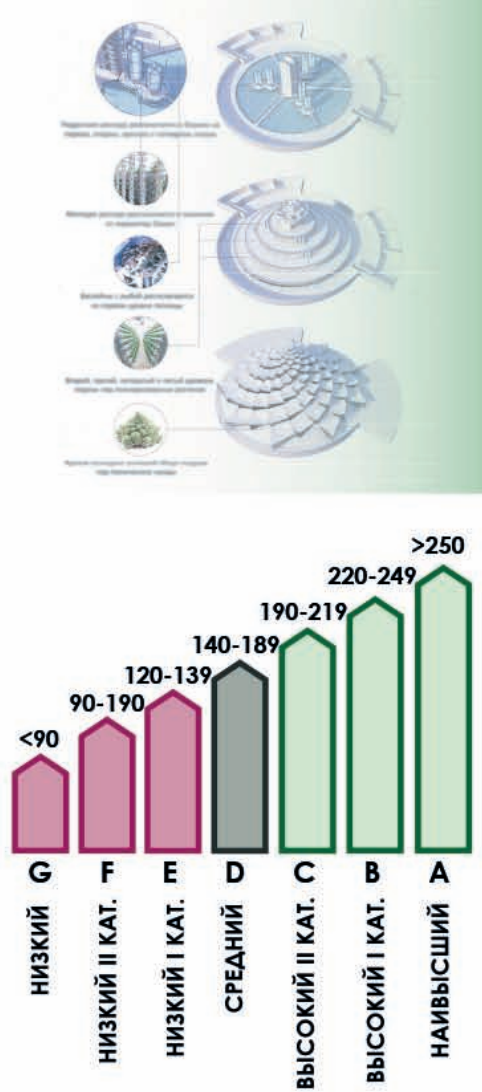

Здание как комплексная устойчивая архитектурно-инженерная система. Графический дизайн схемы Н. Юдиной 


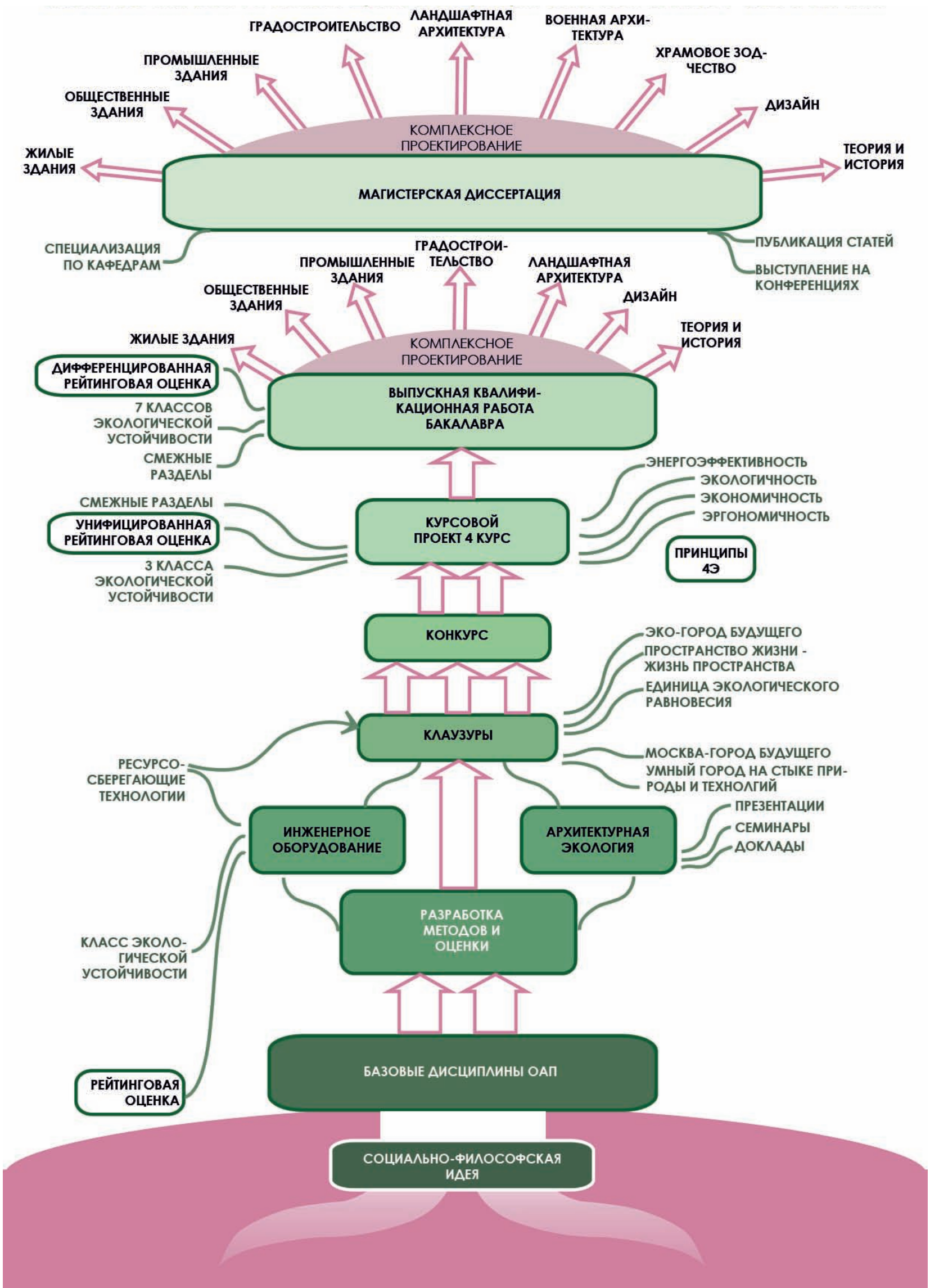

Схема вертикальной интеграции в Концепции экологического образования. Графический дизайн схемы Н.Юдиной 
- Второй принцип - устойчивая среда обитания рассматривается как композиция знаний взаимосвязанных подсистем научных и творческих дисциплин:

- архитектура и градостроительства;

- инфраструктура городов и зданий;

- конструкции зданий и сооружений;

- инженерное оборудование зданий;

- архитектурное материаловедение;

- энергетика, включая использование нетрадиционных возобновляемых источников энергии и вторичных энергоресурсов;

- экология;

- экономика;

- архитектурная физика.

- Третий принцип - трактовка архитектуры как педагогики: архитектура как материально-пространственная среда способствует экологическому просвещению и формированию экологически ответственного поведения человека.

Предложенный педагогический инновационный подход интегрированное архитектурное образование, ориентированное на устойчивое развитие, - отличается тремя ключевыми особенностями:

- переходом от создания комфортных энергоэффективных экологичных зданий к созданию фрагментов устойчивой среды обитания;

- целенаправленно интегрированным междисциплинарным взаимодействием;

- педагогическим воздействием объектов устойчивой среды обитания, которые сами по себе должны способствовать развитию экологического просвещения населения.

\section{Методы и инструменты}

Инструментом оценки результатов освоения принципов устойчивого развития интегрированного устойчивого архитектурного образования стала разработанная система Рейтинговой оценки студенческих курсовых проектов (РОКП).

Рейтинговая оценка развивалась опытным путём, подобно живому организму отражая на разных этапах разработки ключевые проблемы устойчивости среды обитания:

1 этап - энергоэффективность, энергосбережение, использование нетрадиционных возобновляемых источников энергии, управление отходами;

2 этап - качество микроклимата;

3 этап - использование нетрадиционных возобновляемых источников энергии и вторичных энергоресурсов;

4 этап - появление строительных концепций, отражающих энергоэффективность, качество микроклимата, экологичность зданий: энергоэффективное здание, пассивное здание, интеллектуальное здание, экологически нейтральное здание и других;

5 этап - переход к безуглеродным городам;

6 этап - умные технологии для умного дома;

7 этап - от умного дома к умному кварталу;
8 этап - безуглеродные умные города.

Важное отличие предложенной системы рейтинговой оценки студенческих курсовых и дипломных проектов от известных систем состоит в том, что системы, разработанные в МАРХИ, отражают особенности зданий различного назначения:

- система рейтинговой оценки жилых зданий;

- система рейтинговой оценки общественных зданий;

- система рейтинговой оценки промышленных зданий;

- система рейтинговой оценки промышленных зданий сельскохозяйственного назначения;

- система рейтинговой оценки сельскохозяйственных зданий.

- рейтинговая оценка повышения устойчивости среды обитания при реновации существующих зданий

- система рейтинговой комплексной оценки застройки на загрязнённой рекультивируемой территории по принципам экологического «зелёного» строительства (рис. 1, 2).

Студенческие проекты оцениваются путём вычисления рейтинга устойчивости, который отражает оценку показателей всех трёх сфер устойчивости - социальной, экологической, экономической:

- архитектурного облика здания, визуального комфорта;

- качества и экологичности строительных материалов;

- совершенство инженерного оборудования;

- качества микроклимата;

- транспортной доступности;

- создания комфортной среды;

- доступности для маломобильных групп населения;

- водосбережения;

- управления отходами;

- использования нетрадиционных возобновляемых источников энергии и вторичных энергоресурсов;

- использование местных строительных материалов;

- умные технологии;

- инновационные предложения.

В процессе внедрения систем РОКП родилась идея использования дополнительных инструментов и средств интегрированного архитектурного образования в форме:

- клаузуры - эскиза-идея объекта устойчивой среды обитания (sustainable habitat);

- специальных дисциплин, например, «Ресурсосберегающие технологии»;

- стимулирования научной работы студентов - публикация их научных статей.

Клаузура стала основным показателем успешности на промежуточном этапе - перед дипломом на уровне бакалавриата [10].

\section{Примеры инновационного инструмента}

Особого внимания заслуживает тематика клаузур как экспериментальных инновационных эскиз-идей. Например, подготовить студента к внедрению природных процессов в структуру архитектурно-градостроительных объектов и обеспечить безопасность и экологическую устойчивость проектируемой 
урбанизированной среды. Протекание природных процессов в урбанизированной среде затруднено множеством факторов: плотностью застройки, запечатанностью почвенного слоя, сетью автомобильного магистрального движения. Поэтому, например, тему клаузуры «ЕЭР - единица экологического равновесия» можно рассматривать как новый принцип архитектурно-экологической компенсации неблагоприятных состояний (по выбору):

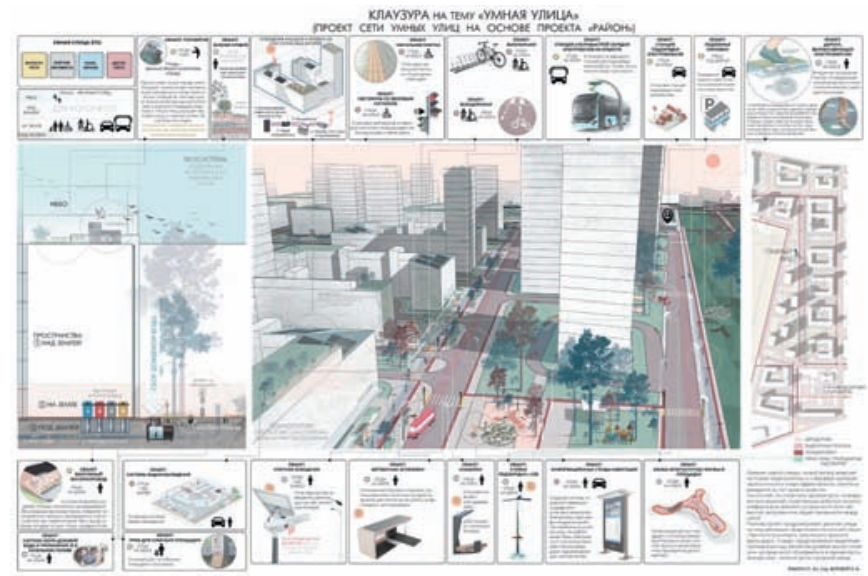

Рис. 3. Клаузура на тему ""Умная" улица». Автор П. Берова

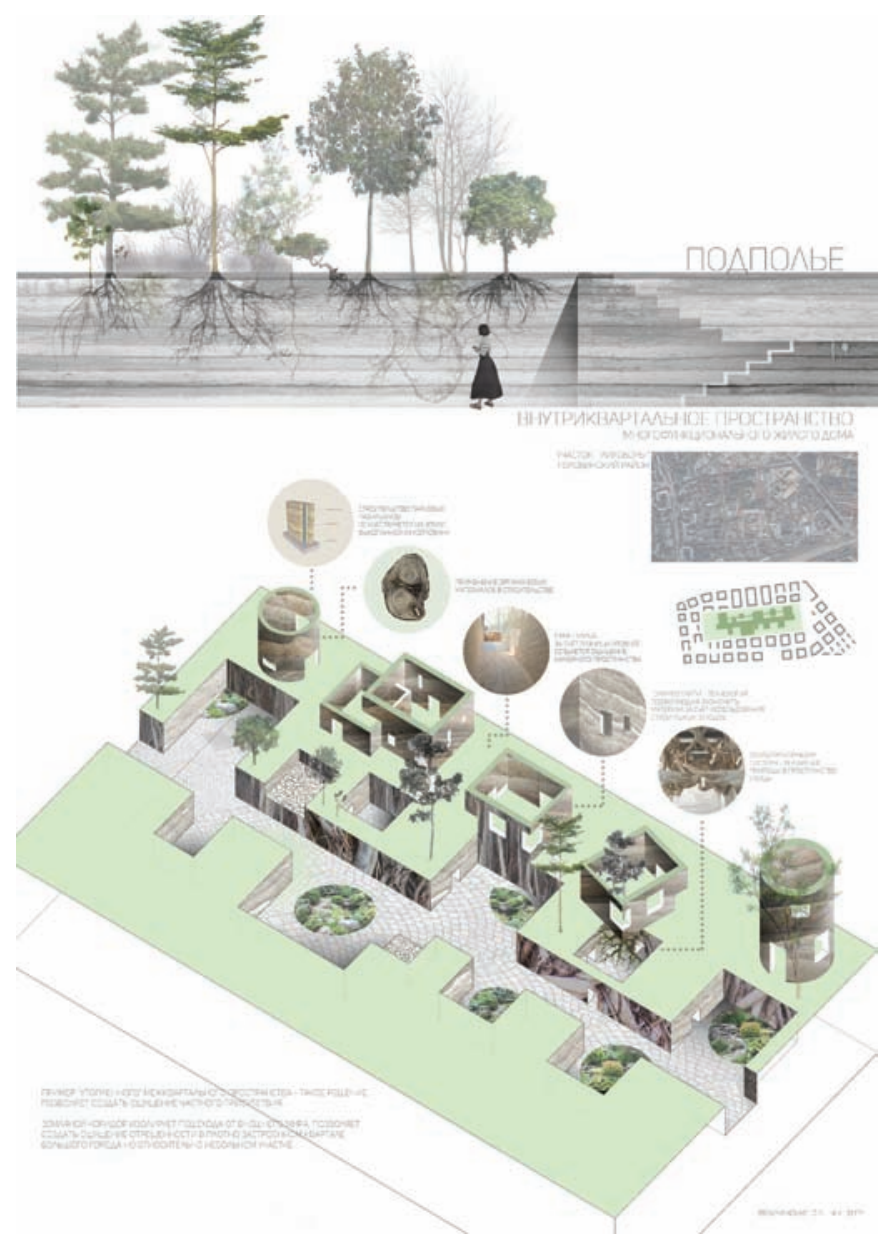

Рис. 4. Клаузура на тему «Внутриквартальное пространство многофункционального жилого дома». Автор С.Л. Величанская
«Мобильное озеленение города», «Внутриквартальное пространство исторической застройки города», «Внутриквартальное пространство жилого дома», «Дом-квартал - архитектурный образ градостроительной экосистемы».

Можно назвать и другие темы, предложенные студентам: «Экогород - город будущего», «Благоустройство общественных пространств города», «Энергоэффективные здания»... Они, как и предыдущий пример, включали несколько конкурсных номинаций, что создавало возможность выбора студентами тем и обеспечивало их заинтересованность в творческом поиске при решении той или иной задачи.

Показательна клаузура 2019 года на тему «Современная архитектура на стыке природы и технологий». Заданием предлагалось разработать инновационные подходы по сбережению и использованию воды, отходов, энергии, транспорта, растительности, которые бы изменили традиционные представления об архитектуре, планировке, ландшафте современного города. Предложенные шесть номинаций: «Дом-модуль», «"Умный" дом», «"Умная" площадь», «"Умные" ресурсы», «"Умный" транспорт, - представляют весь спектр основных требований экологизации среды современного города (рис 3, 4, 5, 6).

Конкурс и выставки клаузур способствуют выработке планки требований к решению этих или иных задач. Клаузуры демонстрируют готовность студентов к решению экологических проблем и проектированию по принципам устойчивого развития, а компетенции, полученные во время лекций и семинаров, подводят их к пониманию связи архитектуры и современных («зелёных») технологий. Информация по проектированию с позиций «зелёной» архитектуры, по мнению студентов, заставляет по-новому взглянуть на задачи архитектуры, рождает новые идеи.

\section{Этапы и методика реализации в образовательном процессе}

Поскольку предложенный подход интегрируется с общим образовательным процессом вуза и ориентирована на внедрение в архитектурное проектирование и выполнение курсовых и архитектурных проектов, то и последовательность этапов (шагов) очень важна.

Шаг первый. Курс инженерное оборудование зданий в седьмом семестре знакомит студентов с разработанной рейтинговой системой оценки здания по классу устойчивости. В следующем 8-ом семестре студенты применяют В своём проекте на конкретном объекте предложенную систему оценки.

Шаг второй. Курс «Архитектурная экология» даёт студенту представление о городе, как об урбанизированной экосистеме, в которой протекают природные процессы; показываются основные проблемы, создающие препятствия для жизни горожан в экологически устойчивом поселении.

Шаг третий. Полученные в архитектурном и инженерном теоретических курсах знания подготавливают студента к 
выполнению клаузуры, которая рассматривается как инновационный инструмент учебного процесса по созданию экологически устойчивой городской среды и завершается конкурсом и выставкой лучших клаузур, что мотивирует студента к творческому решению задач, способствующих процессам экологически устойчивой урбанизации.

Шаг четвёртый. Завершающий четвёртый курс курсовой проект, выполняемый с учётом принципов «4Э», включает рейтинг устойчивости архитектурного объекта.

Шаг пятый. На пятом курсе в преддипломном девятом семестре студенты совершенствуют полученные навыки проектирования по принципам устойчивого развития. Свои разработки они демонстрируют в докладах на научно-практических семинарах и в научных публикациях.

Шаг шестой. К десятому, дипломному, семестру студент овладевает принципами проектирования с учётом экологических требований. Он способен ориентироваться в практике, участвовать в подготовке планов городской застройки и землепользования с учётом существующих экологических рисков.

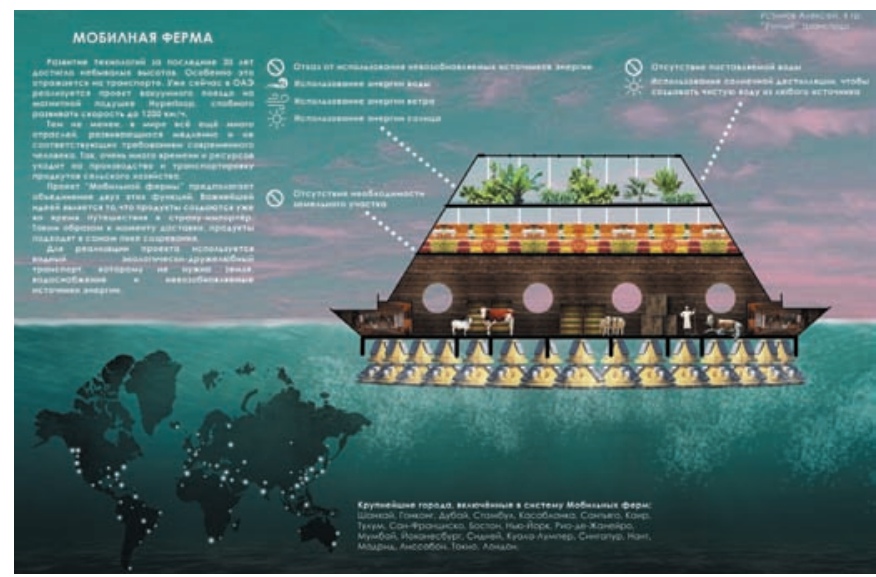

Рис. 5. Клаузура на тему ""Умный" транспорт». Автор А. Устинов

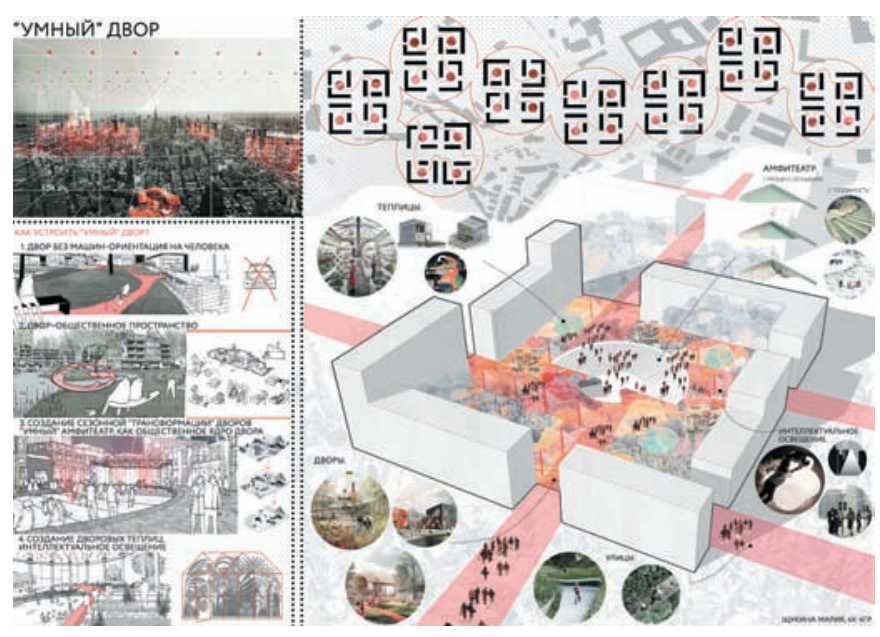

Pис. 6. Клаузура на тему «"Умный" двор». Автор М. Щукина
Шаг седьмой. Умение комплексно решать глобальные экологические задачи в архитектурно-градостроительных проектах при поступлении в магистратуру позволяет архитектору-бакалавру преодолеть вступительный экзамен и выбрать тему магистерской диссертации, связанную с решением актуальных задач, ориентированных на обеспечение нового высокого качества среды жизнедеятельности для всех поколений.

Предложенный в Московском архитектурном институте научно-педагогический подход прошёл апробацию в течение 2013-2020 годов и доказал эффективность, заложенную в его системности, осуществлённой корректировке программ преподавания целого ряда дисциплин, их экологической ориентации и интеграции в решении проектных задач.

Распространение экологических знаний, проектирование объектов как архитектурно-инженерных систем на принципах устойчивого развития способствует росту интереса студентов и педагогов, ведущих архитектурное проектирование и на начальном этапе обучения. Это проявляется в тематике кур-

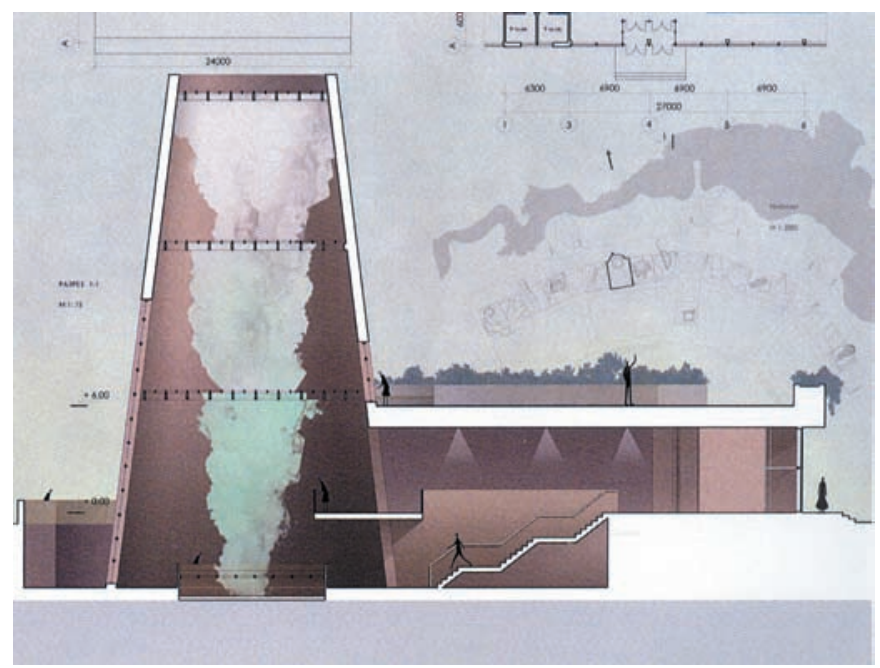

a)

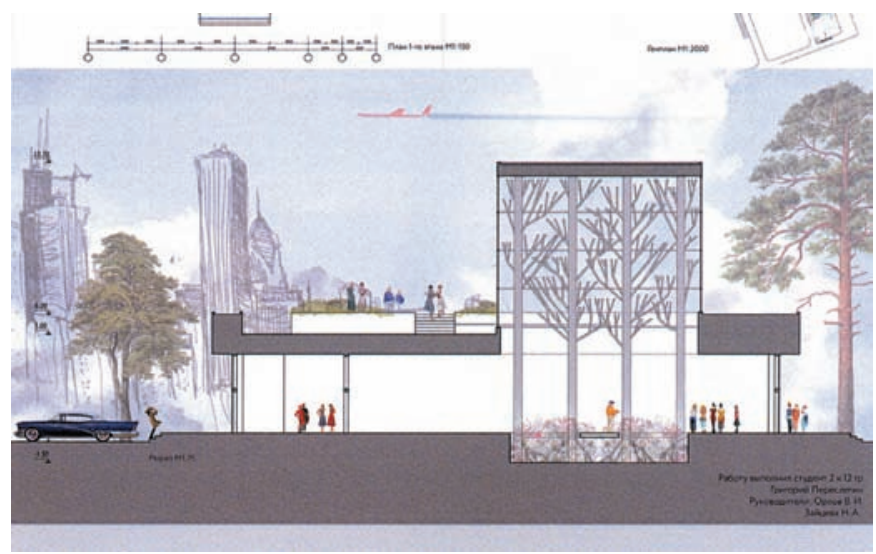

б)

Рис. 7. Клаузуры на тему «Выставочные павильоны: “Экология города"». Руководители В.И. Орлов и Н.А. Зайцева. Авторы: а) И. Лисов; б) Г. Переслегин 
совых проектов и оигинальном подходе к решению проектных задач. Например, разработка конкурсной темы «Выставочные павильоны. “Экология города. Под одной крышей”» (рис. 7).

\section{Заключение}

Охват всех этапов бакалавриата и магистратуры воздействием в концепции интегрированного архитектурного образования, ориентированного на Стратегию устойчивого развития, показал, что это обеспечивает формирование мировоззрения архитекторов и их способности решать задачи создания устойчивой среды обитания:

в социальной сфере - создание архитектурных объектов, отвечающих требованиям обеспечения охраны здоровья и безопасности, достойных условий труда, доступности для маломобильных групп населения, способствующих здоровому образу жизни;

в экологической сфере - строительство и эксплуатация зданий в соответствии с «зелёными» принципами, безуглеродных городов, использование нетрадиционных возобновляемых источников энергии и вторичных энергоресурсов, управление отходами, развитие экологического транспорта, использование экологичных строительных материалов;

в экономической сфере - региональное развитие, ограничение разрастания мегаполисов, содействие созданию рабочих мест, продвижение городов как центров туризма, содействие их благоустройству и росту привлекательности.

Умение комплексно решать глобальные экологические задачи в архитектурно-градостроительных проектах позволит архитектуру - бакалавру и магистру - решать задачи, поставленные в Национальных проектах ради достижения нового качества жизни для всех поколении, которое может быть обеспечено только при динамическом развитии России, учёте факторов форсайт-проектирования на принципах устойчивого развития.

Подводя итог, отметим, что в XXI веке востребована новая культура человечества - экологическая, которая определяет ценностные ориентации, мотивирующие экологически обоснованное поведение и деятельность, обеспечивающая новый качественный уровень отношений между человеком и социоприродной средой. В широком смысле - экологическая культура есть новое содержание общечеловеческой культуры. В этом контексте разработанные в МАРХИ инновационные принципы, вертикально интегрированные в архитектурно-градостроительное проектирование, создают предпосылки формирования архитектора новой экологической культуры, владеющего способностью реализовывать принципы устойчивого развития.

\section{Лumepamypa}

1. Leicht, Alexander. Issues and trends in Education for Sustainable Development / Leicht, Alexander, Heiss, Julia, Won Jung Byun. - Paris : UNESCO, 2018. pp. 26, 27.

2. Bihn, K. Nguyen. Comparative review of five sustainable rating systems / Bihn K. Nguyen, Hasim Altan // UK Proceedia Engineering 21. - 2011. - P. 376-386
3. Arthur Lyon, Dahl. Achievements and gaps in indicators for sustainability / Arthur Lyon Dahl. // Ecological indicators. - 2012. - 17. - P. 14-19.

4. Margarida, Feria. Architectural design sustainability in decision-making process 2019 [Электронный ресурс ] / Margarida Feria, Miguel Amado // Buildings. - 2019. - № 9 (5). - Р. 135. - Режим доступа: https://doi.org/10.3390/ buildings9050135 (дата обращения 01.02.2020).

5. Brophy, V. A Green Vitruvius Principles and Practice of Sustainable Architectural Design / Brophy, V.; Lewis, 0.J. London UK : Routledge, 2011.

6. Lopes, A. Sustainability through Art / Lopes, A. C., Farinha, J. \& Amado, M. // International Conference on Technologies and Materials for Renewable Energy, Environment and Sustainability. TMREES 2017 / Salame, C-T., Aillerie, M. \& Panagiotis, P. (eds.). - Amsterdam: Elsevier Science BV, 2017. - P. 752-766. (Energy Procedia; vol. 119).

7. Есаулов, Г.В. Устойчивая архитектура: от принципов к стратегии развития / Г.В. Есаулов // Вестник ТГАСУ. - 2014. - № 6. - С. 9-14.

8. Есаулов, Г.В. Концепция экологического образования в архитектурном вузе // Г.В. Есаулов, Н.Г. Благовидова // Архитектура и строительство России. - 2015. - № 9. - С. 2-13.

9. Табунщиков, Ю.А. Энергоэффективные здания / Ю.А. Табунщиков, М.М. Бродач, Н.В. Шилкин. - М. : АВОК-пресс, 2003. - 192 C.

10. Благовидова, Н.Г. Эко-клаузура как лаборатория творческих поисков студента-архитектора : конкурс клаузур студентов 4-го курса на тему «»Эко-будущее Москвы» // Наука, образование и экспериментальное проектирование : Труды МАРХИ. Материалы международной научно-практической конференции. МАРХИ. 2-6 февраля 2018 г. - М. : МАРХИ, 2018. - C 35-48.

11. Есаулов, Г.В. Устойчивое развитие и будущее архитектурного образования / Г.В. Есаулов // Известия высших учебных заведений. Строительство. - 2019. - № 2 (722). - С. 78-85.

\section{References}

1. Leicht, Alexander, Heiss, Julia, Won Jung Byun. Issues and trends in Education for Sustainable Development. Paris, UNESC0, 2018. pp. 26, 27.

2. Bihn K. Nguyen, Hasim Altan. Comparative review of five sustainable rating systems. UK Proceedia Engineering 21, 2011, pp. 376-386.

3. Arthur Lyon Dahl. Achievements and gaps in indicators for sustainability. Ecological indicators, 2012, no. 17, pp. 14-19.

4. Margarida Feria, Miguel Amado. Architectural design sustainability in decision-making process 2019. Buildings, 2019, no. 9 (5), pp. 135. URL: https://doi.org/10.3390/ buildings9050135 (Accessed 01.02.3020).

5. Brophy, V.; Lewis, 0.J. A Green Vitruvius Principles and Practice of Sustainable Architectural Design. London UK, Routledge, 2011. 
6. Lopes, A. C., Farinha, J. \& Amado, M., 2017, Sustainability through Art. International Conference on Technologies and Materials for Renewable Energy, Environment and Sustainability. TMREES 2017, Salame, C-T., Aillerie, M. \& Panagiotis, P. (eds.). Amsterdam, Elsevier Science BV, p. 752-766 (Energy Procedia; vol. 119).

7. Esaulov G.V. Ustoichivaya arkhitektura: ot printsipov k strategii razvitiya [Sustainable architecture: from principles to development strategies]. Vestnik TGASU [Bulletin of TGASU], 2014, no. 6, pp. 9-14.

8. Esaulov G.V. Blagovidova N.G. Kontseptsiya ekologicheskogo obrazovaniya $v$ arkhitekturnom vuze [The concept of environmental education in an architectural university]. Arkhitektura i stroitel'stvo Rossii [Architecture and construction of Russia], 2015, no. 9, pp. 2-13.

9. Tabunshchikov Yu.A. Brodach M.M., Shilkin N.V. Energoeffektivnye zdaniya [Energy efficient buildings]. Moscow, AVOK-press Publ. 2003, 192 p.
10. Blagovidova N.G. Eko-klauzura kak laboratoriya tvorcheskikh poiskov studenta-arkhitektora: konkurs klauzur studentov 4-go kursa na temu «Eko-budushchee Moskvy» [Eco-clause as alaboratory for the creative search of a studentarchitect: competition for the fourth-year student clause on the topic "Eco-future of Moscow"]. Nauka, obrazovanie $i$ eksperimental'noe proektirovanie : Trudy MARKhI. Materialy mezhdunarodnoi nauchno-prakticheskoi konferentsii [Science, Education and Experimental Design: Proceedings of the Moscow Architectural Institute. Materials of the international scientificpractical conference. MARKhI. February 2-6, 2018]. Moscow, MARKhI Publ., 2018, pp. 35-48.

11. Esaulov G.V. Ustoichivoe razvitie $\mathrm{i}$ budushchee arkhitekturnogo obrazovaniya [Sustainable development and the future of architectural education]. Izvestiya vysshikh uchebnykh zavedenii. Stroitel'stvo [News of higher educational institutions. Construction], 2019, no. 2 (722), pp. 78-85.

Есаулов Георгий Васильевич (Москва). Доктор архитектуры, профессор, академик РААСН. Проректор по научной работе ФГБОУ В0 «Московский архитектурный институт (государственная академия)» (107031, Москва, ул. Рождественка, 11. МАРХИ); вице-президент Российской академии архитектуры и строительных наук (107031, Москва, Большая Дмитровка, 21. РААСН). Эл.почта: science@markhi.ru.

Табунщиков Юрий Андреевич (Москва). Доктор технических наук, профессор, член-корреспондент РААСН. Заведующий кафедрой «Инженерное оборудование зданий и сооружений» ФГБОУ ВО «Московский архитектурный институт (государственная академия)» (107031, Москва, ул. Рождественка, 11. МАРХИ). Эл.почта: tabunschikov@abok.ru.

Благовидова Наталия Георгиевна (Москва). Кандидат архитектуры. Профессор кафедры «Градостроительство» ФГБОУ В0 «Московский архитектурный институт (государственная академия)» 107031, Москва, ул. Рождественка, 11. МАРХИ). Эл.почта: nablago7@yandex.ru.

Esaulov Georgy Vasilievich (Moscow). Doctor of Architecture, Professor, Academician of RAACS. Vice-Rector of the Moscow Institute of Architecture (11 Rozhdestvenka st., Moscow, 107031. MARCHI). Vice-President of the Russian Academy of Architecture and Construction Sciences (24 Bolshaya Dmitrovka St., Moscow, 107031,RAACS). E-mail: science@markhi.ru.

Tabunshchikov Yuri Andreevich (Moscow). Doctor of Technical Sciences, Professor, Corresponding Member of RAACS. Head of the Department of Engineering Equipment for Buildings and Structures of the Moscow Institute of Architecture (11 Rozhdestvenka st., Moscow, 107031. MARCHI). E-mail: tabunschikov@abok.ru.

Blagovidova Natalia Georgievna (Moscow). Candidate of Architecture. Professor at the Department of Urban Planning of the Moscow Institute of Architecture (11 Rozhdestvenka st., Moscow, 107031. MARCHI). Email: nablago7@yandex.ru. 